\title{
PLAN4BUSINESS - A SERVICE PLATFORM FOR AGGREGATION, PROCESSING AND ANALYSIS OF URBAN AND REGIONAL PLANNING DATA
}

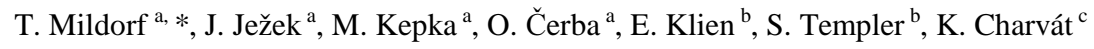

\author{
${ }^{a}$ University of West Bohemia, Geomatics section, Univerzitni 8, 30614 Pilsen, Czech Republic - (mildorf, jezekjan, \\ mkepka, cerba)@kma.zcu.cz \\ ${ }^{\mathrm{b}}$ Fraunhofer IGD, Fraunhoferstraße 5, 64283 Darmstadt, Germany - (klieneva.klien, simon.templer)@ igd.fraunhofer.de \\ ${ }^{\mathrm{c}}$ Help Service Remote Sensing, Vnoučkova 614, 25601 Benešov, Czech Republic - kch@hsrs.cz
}

KEY WORDS: Spatial planning, integration engine, analysis engine, plan4business, INSPIRE, data heterogeneity, data harmonisation.

\begin{abstract}
:
The paper presents the main objectives of the plan4business project that aims to develop a service platform for integration, analysing and presenting spatial planning data. The platform should serve as a catalogue of planning data enabling user automated data integration and spatial analyses. The contribution presents the approach for data integration, relation to INSPIRE and the technical solution for data analysis.
\end{abstract}

\section{INTRODUCTION}

Current trend in the EU is to open access to information of public administration. Information is provided either for free or for marginal costs. Next to EU legislation supporting this process such as the EU Directive on the Re-use of Public Sector Information (PSI Directive), other European initiatives can be recognised, for example the European Interoperability Framework (EIF). All the related legislation and initiatives aim to provide information in an interoperable way suitable for reuse. As identified by recent studies, e.g. by Koski (2011), releasing public sector information for reuse can also have a considerable benefit on the economic growth.

An important part of public sector information represents spatial data. Spatial or geographic data are defined by the International Organization for Standardisation (ISO) as "data with implicit or explicit reference to a location relative to the Earth." (ISO 19109 2005). The importance of spatial data can be illustrated with the economic value of spatial information within the public sector information in the EU (see Figure 1), which was numbered to 35.8 Billion EUR in 1999.

This paper focuses on spatial data used for or resulting from spatial planning activities and their reuse. Spatial planning "gives geographical expression to the economic, social, cultural and ecological policies of society. It is at the same time a scientific discipline, an administrative technique and a policy developed as an interdisciplinary and comprehensive approach directed towards a balanced regional development and the physical organisation of space according to an overall strategy." (Council of Europe 1983).

Spatial planning data perceived by the authors include mainly land use data as defined by the INSPIRE Directive. Land use is defined as the "territory characterised according to its current and future planned functional dimension or socio-economic purpose (e.g. residential, industrial, commercial, agricultural, forestry, recreational)." (European Commission 2010a). Next to land use data, spatial planning data encompass statistical data, hydrography, flood areas, protected sites, transport network, cadastral parcels and other data used for spatial planning activities.

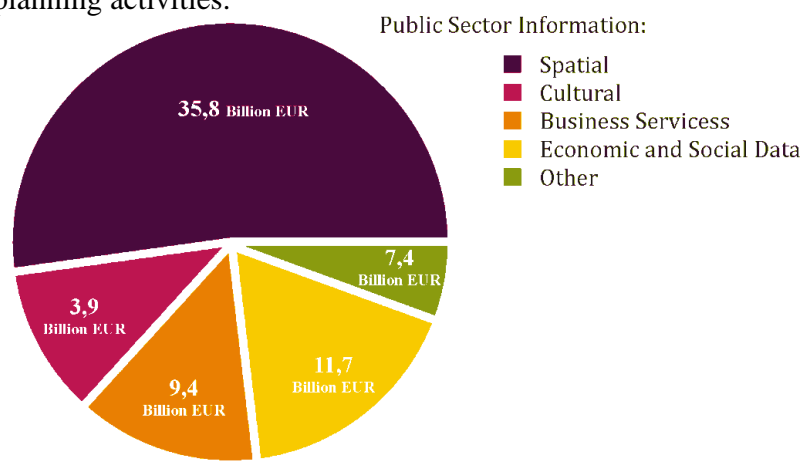

Figure 1: Economic value of public sector information in the European Union in 1999 (Pira International Ltd. \& University of East Anglia and KnowledgeView Ltd. 2000).

This paper introduces the objectives of the plan4business project that aims to create a service platform for aggregating, processing and analysing spatial planning data. The authors focus on the technical solution related to the exploitation of spatial planning data.

\section{DATA HETEROGENEITY, HARMONISATION AND PLAN4BUSINESS PLATFORM}

Considering the importance of spatial planning data for society, there are important issues which need to be addressed in order to achieve sustainable reuse of spatial planning data. The Geographic Information Panel (2008) declares that "current users of spatial information spend 80 per cent of their time collating and managing the information and only 20 per cent analysing it to solve problems and generate benefits."

Heterogeneity of spatial planning data hinders their integration, reuse and better exploitation on pan European level and in cross border applications. Heterogeneity of spatial data was 
demonstrated by many projects such as HUMBOLDT $^{1}$ or Plan4all $^{2}$ and initiatives such as INSPIRE ${ }^{3}$. The spatial data heterogeneity include not only different formats and application schemas, but also different quality, classification systems, terminology and feature catalogues.

The requirements of research institutes, spatial planners, decision makers and other stakeholders show the growing need for spatial planning data harmonisation and analyses of spatial planning data (Vancutsem et al. 2012). Data harmonisation is defined by INSPIRE as "providing access to spatial data through network services in a representation that allows for combining it with other harmonised data in a coherent way by using a common set of data product specifications." (European Commission 2010b).

The aspects of spatial planning data harmonisation and analysis are researched by the plan4business project. Plan4business is a European project running from April 2012 until March 2014, co-financed by the $7^{\text {th }}$ Framework Programme of the European Commission. The platform envisioned by the project will serve as a catalogue of planning data enabling user data integration and spatial analyses.

The plan4business platform is composed of three layers as depicted in Figure 2:

1. Client layer - user interface for performing data integration, management, analyses and visualisation.

2. Integration and analysis layer - engines for data harmonisation and data analyses. It includes API (Application Programming Interface) for better exploitation of the plan4business platform features in other applications.

3. Storage layer - optimised storage for data and metadata.

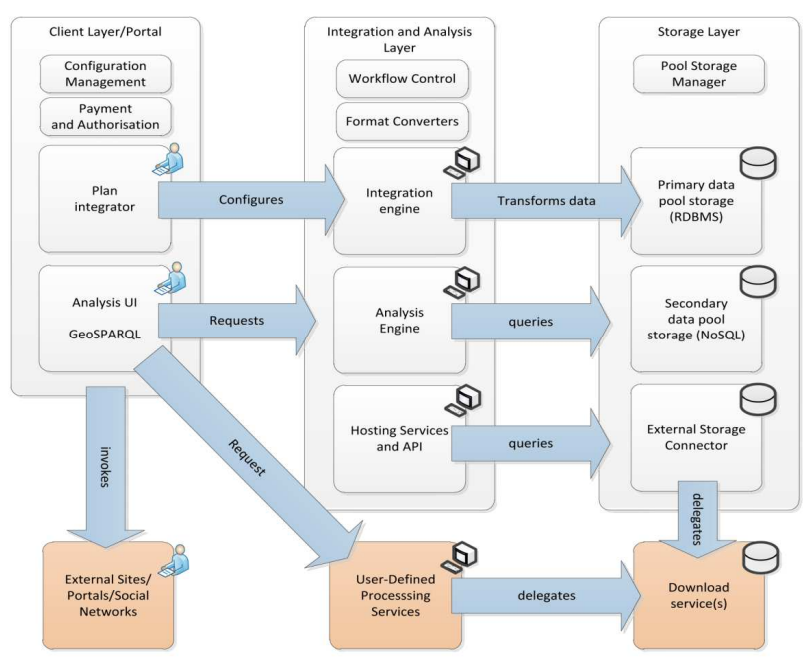

Figure 2: The components of the Plan4business platform (Fraunhofer 2012).

The plan4business platform aggregates the following types of spatial planning data:

1. urban and regional planning data from different countries;

2. land use data including GMES Urban Atlas data and Corine Land Cover;

3. Open Street Map data as representative of traffic and as a key reference dataset;

\footnotetext{
${ }^{1}$ http://www.esdi-humboldt.eu

${ }^{2} \mathrm{http}: / /$ www.plan4all.eu

${ }^{3} \mathrm{http}: / /$ inspire.jrc.ec.europa.eu/
}

4. Natura 2000 data as information about potential restriction coming from environment protection;

5. market information (number of properties, sale transactions, price levels);

6. social and economic data (e.g. Eurostat data);

7. individual property data (legal status, current use) and cadastral parcels.

The diversity of input data is one of the main challenges for the plan4business project. The solution for data integration is based on the experience of the project partners from previous projects including HUMBOLDT and Plan4all.

The next two chapters elaborate the two main components of the plan4business platform - the Integration and the Analysis Engines - that enable the automation of harmonisation processes and the possibility to perform complex spatial requests across various data sources Europe wide.

\section{INTEGRATION ENGINE}

The Integration Engine is one of the core components of the plan4business system. It is intended to perform all data transformations necessary to seamlessly integrate heterogeneously structured, externally provided spatial vector data into the plan4business pool of homogeneously structured vector planning data.

Based on the input data, the Integration Engine should be deployed on the server side of the plan4business platform and transforms input data to the common database schema. In this process, various conversions and transformations steps such as mapping between different data formats, geometric representations and conceptual schemas will have to be performed by the integration engine. This functionality will be implemented on top of the functionality of the Humboldt Alignment Editor $^{4}$ (HALE), a desktop software that was initiated within the EU funded HUMBOLDT project (FP6) and is continuously developed as an open source software under the lead of the Data Harmonisation Panel ${ }^{5}$.

In the scope of plan4business, however, the actual data transformation will be performed on the server. It will be possible to perform several data transformation processes that are initiated by different users at the same time. Furthermore the transformed data is not to be written to an output file within the file system but directly to a database so it can potentially be concurrently retrieved, analysed or extended in a resourceefficient and consistent way.

The scope of plan4business is focused on spatial planning data and its lifecycle is moving faster than the INSPIRE initiative as a whole. It is neither feasible nor functionally required to address and implement each of the 34 themes of the INSPIRE data specifications. In order to reduce the complexity of the resulting data model for plan4business, themes that are not relevant for the identified use cases of the plan4business system or where no suitable source data sets can be obtained are not handled. In addition, individual details of those themes that were selected for plan4business will be omitted for at least the initial implementation. However, during the project lifecycle the initially selected subset of relevant INPIRE themes and the set of adapted features of the themes can be extended as needed.

As a starting point the INSPIRE Land Use theme was selected. It covers the most fundamental aspect of the data relevant for plan4business. This theme can be used to capture spatial data sets that describe existing or planned land use or spatial plans.

\footnotetext{
${ }^{4}$ http://dhpanel.eu/humboldt-framework/hale.html

${ }^{5}$ http://dhpanel.eu
} 
Each dataset aggregates a (non-empty) set of LandUseObjects that are either ExistingLandUseObjects (for a LandUseDataSet) or ZoningElements (for a SpatialPlan). All LandUseObjects provide information about their spatial extent, the time period for which they are valid and are classified according to the Hierarchical INSPIRE Land Use Classification System (HILUCS).

\section{ANALYSIS ENGINE}

The Analysis Engine is one of the plan4business platform components enabling analysis of spatial planning data stored in a relational database. User defined queries can be processed, visualised and downloaded. An example of a query can be to find areas for residential buildings which cannot be affected by floods and which are easily accessible by public transport.

It enables accessing and processing spatial planning data and their retrieval for visualisation in the map client. The Analysis Engine provides access to all analytical functions of the spatial database.

The plan4business platform uses the open source PostgreSQL database with the PostGIS support programme for spatial data. While the analysed data are stored in various database schemas, the results of analyses are stored in a single schema. The results in that schema are organised through the stored_query table depicted in Figure 3. The table contains the following information:

1. query_id - query identifier is used for data management,

2. sql_query - original user defined SQL query for the analysis,

3. result_table_name - name of the result table,

4. time_stamp -continuously changing time stamp indicating either the time of the query initiation, editing or finalisation,

5. processing_state - the status of the current process: in process, finalised, deleted,

6. geometry_column - geometry type that can be used for visualisation of queries with particular geometry,

7. user_id - identifier of the user who set the query and has the right to edit it,

8. used_time - an indication whether time is used in the query as another dimension.

\begin{tabular}{|ll|}
\hline \multicolumn{2}{|c|}{ stored_query } \\
\hline query_id & BIGINT \\
sql_query & CHARACTER VARYING $(4000)$ \\
result_table_name & CHARACTER VARYING(60) \\
time_stamp & TIMESTAMP WITH TIME ZONE \\
processing_state & CHARACTER VARYING(600) \\
geometry_column & CHARACTER VARYING $(20)$ \\
user_id & CHARACTER VARYING $(30)$ \\
used_time & BOOLEAN \\
\hline
\end{tabular}

\section{select_1355249654959}

Figure 3 Metadata table containing the information about the analysis result (Ježek et al. 2013)

Each record contains a unique identifier for securing the connection between the query and the results. All database operations are managed by the database functions that also ensure data consistency by utilising fully transactional behaviour.
The main part of the Analysis Engine runs on a server. This part ensures communication with users and forwarding requests to the database. Two main modules and one supportive module can be distinguished.

The first module ensures the reception of user queries and execution of the requests in the database. A query is received by a servlet through the HTTP protocol, the quality of the mandatory parameters is checked and method for further processing is selected based on the combination of the parameters. User query is stored together with other parameters into an object that can be then stored in Query Repository (the stored_query table). At the same time, the query is processed into an SQL command. This results in a new table. The object is then stored into the stored_query table together with the status of the query execution. The status is changed to as soon as the execution of the query is successfully finished.

The second module provides publication of user queries' results. A servlet receives user requirements from the portal and then retrieves data from the database. The user requirement includes identification of the original query and bounding box of the map window where the results will be displayed. In the next version of this module, additional parameters for data visualisation, such as coordinate reference system, are envisaged. As soon as user requirements are received and parameters are checked, a utility for data retrieval from the database is called based on the combination of the parameters. Retrieved data are then converted from objects into the hashmap structure, which corresponds with the structure of the resulting KML file. Only the geometry is retrieved from the database directly in the KML format. Templates for data publication are applied to the resulting files before they are sent to the portal.

The results of the analysis are in the KML format that can be visualised in any map client supporting KML such as Google Earth. The prototype of the plan4business platform is available at http://www.urbanplan-business.eu/.

\section{CONCLUSIONS}

The plan4business project should significantly contribute to decision making processes on various governmental levels and in cross-border activities. The role of spatial planning data in our modern society is increasingly important. Spatial planning data help us to shape the environment we live in, to manage the resources we possess and to preserve our cultural heritage.

This paper presented the technical solution for the service platform that should enable integration and analysis of spatial planning data in Europe. Next to the issues of data integration and analysis, the plan4business consortium is facing challenging problems of data availability and business model to be used.

\section{REFERENCES}

Council of Europe, 1983. European regional/spatial planning Charter.

European Commission, 2010a. Feature Concept Dictionary. Available at: https://inspire-

registry.jrc.ec.europa.eu/registers/FCD [Accessed March 25, 2013].

European Commission, 2010b. INSPIRE Glossary. Available at: http://inspire- 
registry.jrc.ec.europa.eu/registers/GLOSSARY [Accessed February 17, 2012].

Fraunhofer-Gesellschaft zur Foerderung der Angewandten Forschung e. V., 2012. Seventh Framework Programme, Grant Agreement No 296282 plan4business - A service platform for aggregation, processing and analysis of urban and regional planning data, Annex I - Description of Work.

Geographic Information Panel, 2008. Place matters: the Location Strategy for the United Kingdom, Great Britain. International Organization for Standardization, 2005. ISO 19109 - Geographic information - Rules for application schema. Available at:

http://www.iso.org/iso/iso_catalogue/catalogue_tc/catalog ue_detail.htm?csnumber=39891 [Accessed June 21, 2011].

Ježek, J., Kepka, M. \& Mildorf, T., 2013. plan4business SERVISNÍ PLATFORMA PRO AGREGACI, ZPRACOVÁNÍ A ANALÝZU ÚZEMNĚ PLÁNOVACÍCH DAT MĚST A REGIONŮ. In Sborník sympozia GIS Ostrava 2013. Sympozium GIS Ostrava 2013. Ostrava: Vysoká škola báňská - Technická univerzita.

Koski, H., 2011. Does Marginal Cost Pricing of Public Sector Information Spur Firm Growth?

Pira International Ltd. \& University of East Anglia and KnowledgeView Ltd., 2000. Commercial exploitation of Europe's public sector information, Luxembourg: Office for Official Publications of the European Communities. Available at: http://www.ecgis.org/docs/F15363/PIRA.PDF [Accessed August 3, 2011].

Vancutsem, D., Elisei, P. \& Øverli, T.G., 2012. D3.1

Requirements Analysis and System Specification, plan4business consortium.

\section{ACKNOWLEDGEMENTS}

All the authors are supported by the FP7 project plan4business (Grant agreement no: 296282).

The authors from the University of West Bohemia are additionally supported by the European Regional Development Fund (ERDF), project "NTIS - New Technologies for the Information Society", European Centre of Excellence, CZ.1.05/1.1.00/02.0090. 